\title{
Assessment of medication adherence among hypertensive patients: a cross-sectional study
}

\author{
Anup Bhusal*, Pradeep R. Jadhav, Yeshwant A. Deshmukh
}

Department of Pharmacology, MGM Medical College and Hospital, Navi-Mumbai, India

Received: 04 June 2016

Accepted: 04 July 2016

\section{*Correspondence to:}

Dr. Anup Bhusal,

Email: bhusalanup@gmail.com

Copyright: (C) the author(s), publisher and licensee Medip Academy. This is an openaccess article distributed under the terms of the Creative Commons Attribution NonCommercial License, which permits unrestricted noncommercial use, distribution, and reproduction in any medium, provided the original work is properly cited.

\begin{abstract}
Background: Hypertension affects around one billion individuals worldwide and is expected to increase by $29 \%$ to reach 1.56 billion by 2025 . It is usually asymptomatic, chronic disorder needing lifelong treatment. The objective of this study was to study the medication adherence among hypertensive patients using hill-bone compliance to high blood pressure therapy scale (HILL-BONE CHBPTS) and to compare medication adherence in hypertensive patients with controlled and uncontrolled blood pressure.

Methods: A cross-sectional, observational study was conducted for a period of one year in the Outpatient department of Medicine in a tertiary care hospital, Navi Mumbai. A total of 129 hypertensive patients who were on at least six months on antihypertensive medications were enrolled. Blood pressure was measured and details of drug therapy were noted. Medication adherence was assessed using HILL-BONE CHBPTS and respective scores were calculated.

Results: HILL-BONE CHBPTS scores were on the higher side signifying poor medication adherence among hypertensive patients. HILL-BONE CHBPTS score correlated significantly in a positive direction with diastolic blood pressure, duration of treatment and the number of medications, As per JNC 8 recommendations, 58.9\% (76) hypertensive patients were having blood pressure under control, whereas $41.1 \%$ (53) were having uncontrolled blood pressure. HILL-BONE CHBPTS scores were significantly higher (reflecting lower adherence) in hypertensive patients with uncontrolled blood pressure than those having optimally controlled blood pressure.

Conclusions: Overall the medication adherence was poor in hypertensive patients. Adherence to therapeutic regimens is an important factor in blood pressure control among hypertensive patients and needs priority. Health education related to medication adherence needs be improved in hypertensive patients.
\end{abstract}

Keywords: Patient compliance, Medication adherence, Hypertension, Hill bone compliance, HILL-BONE CHBPTS

\section{INTRODUCTION}

Hypertension affects around one billion individuals worldwide and is expected to increase by $29 \%$ to reach 1.56 billion by 2025 . $^{1}$ It is usually asymptomatic, chronic disorder needing lifelong treatment. ${ }^{2,3}$ Though treatment of hypertension is evolving in response to newer drugs and published evidences, it still remains poorly controlled in developed and developing countries. ${ }^{2-8}$ Studies conducted worldwide have documented non-adherence to recommended medication therapy. ${ }^{7-13}$ Adherence and compliance are often interchangeable synonymous terms.
Adherence is referred as "active, voluntary, and collaborative involvement of the patient in a mutually acceptable course of behaviour to produce a therapeutic result. $^{14-18}$ In patients with hypertension, adherence to medication is critically important for controlling blood pressure and reducing associated risk of cardiovascular complications. ${ }^{19}$

In India, the prevalence of hypertension is rising steeply. The overall prevalence is around $29.6 \%$ with regional variations in rural $(27.6 \%)$ and urban $(33.8 \%)$ population. The hypertension control among hypertensive in urban 
and rural parts of India is low $(6.5 \%-15 \%$ in rural and $11.6 \%-28.7 \%$ in urban). ${ }^{8}$ Few studies have addressed the issue of non-adherence in Indian hypertensive patients. ${ }^{20-23}$ Therefore, this study was conducted to find out the medication adherence in hypertensive patients using hill-bone compliance to high blood pressure therapy scale (HILL-BONE CHBPTS) and compared medication adherence in hypertensive patients with optimal controlled and uncontrolled blood pressure.

\section{METHODS}

This was a prospective, cross-sectional, observational study conducted in the outpatient department of Medicine at a tertiary care teaching hospital in Navi Mumbai. Ethical clearance was obtained from the institutional ethics committee (MGM IEC letter number: 2014/SC3/48). The study duration was one year and was conducted from March 2014 to February 2015. The sampling method was convenient and sample size $(n=129)$ included hypertensive patients surveyed during the study period.

\section{Research instrument}

Hill-Bone compliance to high blood pressure therapy scale (HILL-BONE CHBPTS) was used to assess medication adherence level in this study. The scale has good validity and internal reliability. ${ }^{24-27}$ The original HILL-BONE CHBPTS consisted of 14 questions/items having 3 subscales under behavioural domains of hypertension treatment which included

- Medication adherence

- Reduced salt intake and

- Appointment keeping.

Each question/item was answered with a four-point Likert scale ranging from 1 to 4 (1= none of time, $2=$ some of the time, $3=$ most of time, and $4=$ all the time). ${ }^{24}$ In the present study, HILL-BONE CHBPTS which included a nine-item medication adherence subscale was used. ${ }^{26,27}$ Medication adherence subscale score ranged from 9 (perfect adherence) to 36, with higher scores reflecting poorer medication adherence/compliance with antihypertensive drug therapy. Total HILL-BONE CHBPTS score ranged from 14 (perfect adherence) to 56 (non-adherence) with higher scores denoting overall poorer adherence.

In this study, known/diagnosed patients of hypertension aged 18 years or more attending medicine outpatient department for follow-ups or consultation/referred from other departments who were on antihypertensive drugs treatment for more than 6 months were included. After finishing consultation with the treating physician, hypertensive patients were approached and consent was taken. Participants were interviewed in the adjacent room and their socio-demographic (name, age, sex, address, marital status, duration of hypertension) and the current antihypertensive drug therapy details (duration of hypertensive treatment, the number of medication and type of drugs) were noted from the case papers. After a period of 10 minute rest, blood pressure (BP) was recorded in sitting position and were administered HILLBONE CHBPTS (which included a nine-item medication adherence subscale).

\section{Blood pressure measurement}

Hypertensive patients' blood pressure (systolic and diastolic in $\mathrm{mm}$ of $\mathrm{Hg}$ ) was recorded with manual mercury sphygmomanometer (diamond deluxe B.P. apparatus) using an appropriate sized cuff. After 10 minutes of rest, blood pressure was recorded in sitting position, with their feet on the floor and arms supported at the level of heart.

\section{Hypertension control status}

Hypertensive patients were further dichotomized into controlled and uncontrolled blood pressure groups based upon achievement of blood pressure goals as per the eighth joint national committee (JNC 8) recommendations. ${ }^{28}$ Hypertensive patients with blood pressure more than or equal to $140 / 90 \mathrm{~mm}$ of $\mathrm{Hg}$ were classified as uncontrolled whereas patients with blood pressure less than $140 / 90 \mathrm{~mm}$ of $\mathrm{Hg}$ were classified as optimally controlled.

\section{Statistical analysis}

Data recorded was entered in Microsoft excel version 2007. Statistical analysis was done using statistical package for the Social Sciences version 17 (Chicago: SPSS Inc). All the values were expressed in actual number, percentage, and mean \pm standard deviation. Spearman's rho test for correlation and Mann Whitney U test for comparison between two groups was used for nonparametric data. Probability "P" value of less than 0.05 was considered as statistically significant.

\section{RESULTS}

Table 1: Characteristic of hypertensive patients enrolled in the study.

\begin{tabular}{|ll|}
\hline Patient Characteristics & $\begin{array}{l}\text { Total hypertensive } \\
\text { patients }(\mathbf{N}=129)\end{array}$ \\
\hline Patients with hypertension & 129 \\
\hline Age (years) & $49.89 \pm 9.07$ \\
\hline Male & $61(47.28 \%)$ \\
\hline Female & $68(52.72 \%)$ \\
\hline $\begin{array}{l}\text { Systolic blood pressure (SBP) } \\
\text { in mm of Hg }\end{array}$ & $140.10 \pm 14$ \\
\hline $\begin{array}{l}\text { Diastolic blood pressure (DBP) } \\
\text { in mm of Hg }\end{array}$ & $90.12 \pm 8.9$ \\
\hline Duration of treatment (years) & $5.31 \pm 3.95$ \\
\hline
\end{tabular}




\begin{tabular}{|ll|}
\hline Number of medications & $2.12 \pm 0.8$ \\
\hline $\begin{array}{l}\text { Hypertensive with Controlled } \\
\text { blood pressure } *\end{array}$ & $76(58.92 \%)$ \\
\hline $\begin{array}{l}\text { Hypertensive with uncontrolled } \\
\text { Blood pressure } *\end{array}$ & $53(41.02 \%)$ \\
\hline $\begin{array}{l}\text { HILL-BONE CHBPTS total } \\
\text { score }\end{array}$ & $25.53 \pm 3.12$ \\
\hline $\begin{array}{l}\text { Medication } \\
\text { adherence/compliance }\end{array}$ & $14.62 \pm 2.11$ \\
\hline Salt usage & $5.67 \pm 1.12$ \\
\hline Appoint keeping & $5.27 \pm 0.93$ \\
\hline
\end{tabular}

*As per Eighth Joint National Committee (JNC 8) recommendations.
In this study, one hundred and twenty nine $(n=129)$ hypertensive patients were analysed. The mean age of the sample was $(49.89 \pm 9.07)$ years. Males were $47.28 \%(\mathrm{n}=$ $61)$ and females were $52.72 \%(n=68)$. The mean systolic blood pressure was $140.10 \pm 14 \mathrm{~mm}$ of $\mathrm{Hg}$ and diastolic blood pressure was $90.12 \pm 8.9 \mathrm{~mm}$ of $\mathrm{Hg}$. Overall, HILLBONE CHBPTS score of the sample was $(25.5 \pm 3.1)$ and medication adherence subscale was $14.62 \pm 2.11$ reflecting poor medication adherence. Table 1 summarizes the characteristic of hypertensive patients and HILL-BONE CHBPTS scores.

Table 2: Hill-bone compliance to high blood pressure therapy scale responses.

\begin{tabular}{|c|c|c|c|c|}
\hline Questions & $\begin{array}{l}\text { None of the } \\
\text { time }\end{array}$ & $\begin{array}{l}\text { Some of the } \\
\text { time }\end{array}$ & $\begin{array}{l}\text { Most of the } \\
\text { time }\end{array}$ & $\begin{array}{l}\text { All of the } \\
\text { time }\end{array}$ \\
\hline $\begin{array}{l}\text { How often do you forget to take your hypertension } \\
\text { medicine? }\end{array}$ & $15(11.62 \%)$ & $111(86.04 \%)$ & $3(2.32 \%)$ & $0(0 \%)$ \\
\hline $\begin{array}{l}\text { How often do you decide not to take your hypertension } \\
\text { medicine? }\end{array}$ & $74(57.36 \%)$ & $48(37.20 \%)$ & $7(5.42 \%)$ & $0(0 \%)$ \\
\hline How often do you eat salty food? & $23(17.82 \%)$ & $84(65.11 \%)$ & $19(14.72 \%)$ & $3(2.32 \%)$ \\
\hline $\begin{array}{l}\text { How often do you shake salt on your food before you } \\
\text { eat it? }\end{array}$ & $52(40.31 \%)$ & $60(46.51 \%)$ & $14(10.85 \%)$ & $3(2.32 \%)$ \\
\hline How often do you eat fast/junk food? & $28(21.70 \%)$ & $85(65.89 \%)$ & $16(12.40 \%)$ & $0(0 \%)$ \\
\hline $\begin{array}{l}\text { How often do you make the next appointment before } \\
\text { you leave the doctor's office? } *\end{array}$ & $0(0 \%)$ & $12(9.30 \%)$ & $77(59.68 \%)$ & $40(31 \%)$ \\
\hline How often do you miss scheduled appointments? & $24(18.60 \%)$ & $74(57.36 \%)$ & $31(24.03 \%)$ & $0(0 \%)$ \\
\hline How often do you forget to get prescriptions filled? & $31(24.03 \%)$ & $95(73.64 \%)$ & $3(2.32 \%)$ & $0(0 \%)$ \\
\hline How often do you run out of hypertension Pills? & $32(24.80 \%)$ & $70(54.26 \%)$ & $25(19.37 \%)$ & $2(1.55 \%)$ \\
\hline $\begin{array}{l}\text { How often do you skip your hypertension medicine } \\
\text { before you go to the doctor? }\end{array}$ & $49(37.98 \%)$ & $79(61.24 \%)$ & $1(0.77 \%)$ & $0(0 \%)$ \\
\hline $\begin{array}{l}\text { How often do you miss taking your hypertension pills } \\
\text { when you feel better? }\end{array}$ & $78(60.46 \%)$ & $44(34.10 \%)$ & $7(5.42 \%)$ & $0(0 \%)$ \\
\hline $\begin{array}{l}\text { How often do you miss taking your hypertension pills } \\
\text { when you feel sick? }\end{array}$ & $49(37.98 \%)$ & $75(58.13 \%)$ & $5(3.87 \%)$ & $0(0 \%)$ \\
\hline $\begin{array}{l}\text { How often do you take someone else's hypertension } \\
\text { pills? }\end{array}$ & $121(93.79 \%)$ & $8(6.20 \%)$ & $0(0 \%)$ & $0(0 \%)$ \\
\hline $\begin{array}{l}\text { How often do you miss taking your hypertension pills } \\
\text { when you are careless? }\end{array}$ & $42(32.55 \%)$ & $87(67.44 \%)$ & $0(0 \%)$ & $0(0 \%)$ \\
\hline
\end{tabular}

* reverse coding/scoring.

Responses to individual items of hill-bone compliance to high blood pressure therapy scale are summarized in Table 2. In medication adherence subscale, item "How often do you forget to take your hypertension medicine" $(11.62 \%)$ had the lowest proportion of respondents who answered none of the time followed by item "how often do you forget to get prescriptions filled" $(24.03 \%)$ and item "how often do you run out of hypertension pills" $(24.82 \%)$. In the salt usage subscale, item "how often do you eat salty food" had the lowest proportion of respondents who answered none of the time (17.82\%) while majority responded sometimes $(65.11 \%)$. In the appointment keeping subscale, item "how often do you make the next appointment before you leave the doctor's office" had the highest proportion of respondents who answered all of the time (31\%).

Correlation of HILL-BONE CHBPTS total score with age, systolic BP, diastolic BP, duration of treatment and number of medications are summarized in Table 2. HILLBONE CHBPTS score correlated significantly and in positive direction with diastolic BP $(\mathrm{r}=0.267, \mathrm{p}=0.002)$, duration of treatment $(\mathrm{r}=0.194, \mathrm{p}=0.028)$ and number of 
medications $(\mathrm{r}=0.173, \mathrm{p}=0.049)$ in the entire sample (Table 3).

Hypertensive patients were further dichotomized based upon their blood pressure status as per JNC 8 recommendations. In this study, we found that $58.92 \%$ (76) were having controlled blood pressure while $41.08 \%$ (53) were having uncontrolled blood pressure despite drug therapy (Table 1). HILL-BONE CHBPTS total, medication adherence and salt usage scores were significantly higher in uncontrolled group in comparison with controlled group, suggesting higher non-adherence among uncontrolled hypertensive patients (Table 4).
Table 3: Correlation of total HILL-BONE CHBPTS score with variables of hypertensive patients.

\begin{tabular}{|lll|}
\hline Variables & $\begin{array}{l}\text { Spearman' } \\
\text { s rho (r) }\end{array}$ & P value \\
\hline Age (years) & -0.059 & 0.506 \\
\hline $\begin{array}{l}\text { Systolic blood pressure } \\
\text { (SBP) in mm of Hg }\end{array}$ & 0.155 & 0.080 \\
\hline $\begin{array}{l}\text { Diastolic blood pressure } \\
\text { (DBP) in mm of Hg }\end{array}$ & 0.267 & 0.002 \\
\hline $\begin{array}{l}\text { Duration of treatment } \\
\text { (years) }\end{array}$ & 0.194 & 0.028 \\
\hline Number of medications & 0.173 & 0.049 \\
\hline
\end{tabular}

Table 4: Comparison of hill bone compliance scale score between hypertensive patients with controlled and uncontrolled blood pressure.

\begin{tabular}{|c|c|c|c|}
\hline \multirow{2}{*}{ Variables } & \multicolumn{2}{|c|}{ Blood pressure status } & \multirow{2}{*}{ P value * } \\
\hline & Controlled $(n=76)$ & Uncontrolled $(n=53)$ & \\
\hline \multicolumn{3}{|c|}{ HILL-BONE CHBPTS total score } & \multirow{3}{*}{0.013} \\
\hline Mean \pm SD & $24.89 \pm 3.4$ & $26.45 \pm 2.5$ & \\
\hline Median (inter quartile range) & $25(22,25,28)$ & $26(25,26,29)$ & \\
\hline \multicolumn{3}{|l|}{ Medication adherence } & \multirow{3}{*}{0.048} \\
\hline Mean \pm SD & $14.26 \pm 2.23$ & $15.13 \pm 1.84$ & \\
\hline Median (inter quartile range) & $15(13,15,16)$ & $15(14,15,17)$ & \\
\hline \multicolumn{3}{|l|}{ Salt usage } & \multirow{3}{*}{0.039} \\
\hline Mean \pm SD & $5.51 \pm 1.25$ & $5.90 \pm 0.8$ & \\
\hline Median (inter quartile range) & $5(5,5,6)$ & $6(5,6,7)$ & \\
\hline \multicolumn{3}{|l|}{ Appointment keeping } & \multirow{3}{*}{0.063} \\
\hline Mean \pm SD & $5.13 \pm 0.8$ & $5.47 \pm 1.1$ & \\
\hline Median (inter quartile range) & $5(4,5,6)$ & $6(5,6,6)$ & \\
\hline
\end{tabular}

* P-value by Mann Whitney U test.

\section{DISCUSSION}

The findings of the present study suggest that the medication adherence was poor among hypertensive patients at a tertiary care teaching hospital in Navi Mumbai. Widely variable rates of non-adherence are reported in studies, depending on the type of research scale used. In this study, hill-bone compliance to high blood pressure therapy scale was used. This scale is a reliable, validated scale and specific to hypertensive patients. This scale provides several insights into the participants' compliance with regard to their medication, salt usage and appointment keeping. ${ }^{24,26,27}$

Overall, HILL-BONE CHBPTS scores were on the higher side which signified that the medication adherence was poor and issues of non-adherence in this study. Several studies using different research instrument and systematic reviews have also addressed issues of poor medication adherence/compliance among hypertensive patients. $^{16,20,23,29-31}$ In this study, we identified that hypertensive patients often forgot to take their medications, often forgot to get their prescription refilled, usually ran out of hypertensive pills and often missed their hypertension pills when careless or when they fell sick, thus contributing to lower medication adherence. Our findings are comparable to study conducted by Song et al using hill bone medication adherence in Korean Americans, where they documented poor medication adherence and identified issues of non-adherence in which majority hypertensive patients often forgot to take their medications and often missed their hypertension pills when they felt sick. ${ }^{27}$ Similarly Mafutha et al using hill bone medication adherence documented that medication compliance was good but identified non adherence issues in hypertensive patients in which they often decided not to take their hypertension medicine and often ran out of hypertension medicines. ${ }^{29}$ A study conducted by Ramli et al with medication adherence Scale (modified of HILL-BONE CHBPTS and Morisky medication adherence scale) documented higher proportion of non-adherence. They also addressed nonadherence issues of forgetting, missing and running out of hypertension medications. ${ }^{10}$ 
Indian studies have also documented prevalence of low adherence. Venkatachalam et al documented low adherence prevalence in a rural setting of India using Morisky medication adherence scale. As per the Morisky scale, $51.6 \%$ forget to take medicines regularly, $59.8 \%$ were careless about taking their medications, $53.6 \%$ stop medication on feeling better, and $55.2 \%$ stop medication on feeling worse. ${ }^{23}$ In a study conducted by Santra et al adherence to medication was $20.83 \%, 28.37 \%$ and $32 \%$ in hypertension, congestive cardiac failure, and ischemic heart diseases patients with maximum non-adherence among hypertensive patients. ${ }^{21}$ Dennis et al also documented poor adherence to hypertension treatment and around $78 \%$ patients had difficulty to pay for medication and $54.93 \%$ had difficulty to get a refill on time. $^{20}$ Efforts should always be made to identify the reasons for non-adherence and the steps to be taken to improve it, through better communication between health care providers and hypertensive patients. ${ }^{10}$

In our study, HILL-BONE CHBPTS total score correlated significantly and in a positive direction with duration of treatment, number of medications and diastolic blood pressure. However, some studies have not found a significant correlation with the number of drugs prescribed. ${ }^{32-34}$ But there exists a correlation with number of dosing times per day of all prescribed medications. Similarly, a meta-analysis found that there was a significant difference in compliance rate between patients taking antihypertensive medication once daily and twice daily. ${ }^{32,35,36}$ Another study suggested that longer duration of treatment period might also compromise patient's compliance. ${ }^{37}$ However, some studies about chronic diseases found that longer duration of the disease resulted in good compliance, and newly diagnosed patients had poor compliance. ${ }^{38,39}$ This may indicate that compliance is improved because patient's attitude of denying the disease is reduced and they accepted treatment after years of suffering from the disease.

In this study, we found that $58.92 \%$ were having controlled blood pressure while $41.08 \%$ were having uncontrolled blood pressure as per JNC8 guidelines. These findings are consistent with the studies done by Salanitro et al, Zachariah et al and Weinberger et al which have documented $40 \%-70 \%$ of patients having uncontrolled blood pressure. ${ }^{40-42}$ A study by Elzubier et al using pill counting method documented, $61.6 \%$ had controlled blood pressure while 38.4 had uncontrolled and found that $92 \%$ compliant patients had controlled blood pressure in comparison to noncompliant patients. Major reason for noncompliance was "not able to afford/buy medicines". ${ }^{12}$ Study by Kalil et al using pill counting method documented that, compliance rate was $53 \%$ and degree of blood pressure control was worse among noncompliant subjects. ${ }^{11}$

The pooled estimate for the percentage of hypertensive patients having their BP under control in rural and urban India was $10.7(6.4-15.0)$ and 20.2 (11.6-28.8) respectively. ${ }^{8}$ Although these variations across studies may be true, they may also be due to differences in the populations surveyed, assessment scale, and measurements of blood pressure, utility of different guideline, cut-off levels and type of drug therapy.

In our study, HILL-BONE CHBPTS total and subscale (medication adherence, salt usage) scores were significantly higher (reflecting lower adherence) in hypertensive patients with uncontrolled blood pressure than in comparison with those having optimally controlled blood pressure. This supports the result of various studies that uncontrolled BP occurred in the higher percentage in non-adherent patients compared to adherent group. ${ }^{29,43,44}$ Non-compliance to sodium usage is real and happening in patients with chronic diseases. Bland food due to low salt content does not taste good, which makes it difficult to adhere to a diet low in sodium. ${ }^{45}$ Lifestyle changes focusing on reduction of dietary salt, fat and alcohol and increase in potassium and fruits and vegetables are helpful in hypertension management. ${ }^{46}$ Absenteeism from outpatient appointments is common which reduces clinic productivity and may impact patient outcomes because of missed opportunities for diagnosis and treatment. Technology aided advancements like telephonic reminders; short text messages (SMS) may significantly reduce the failure rate and be cost efficient as seen in chronic respiratory disorders. ${ }^{46}$

The reasons for non-adherence are multi-factorial and complex, involving patient related, physician related and health system-related factors. ${ }^{9,20,31}$ Interventions targeting medication adherence have accomplished modest success. ${ }^{31}$ Optimal blood pressure goals can be achieved by improving adherence to therapy through multimodal approach. Family physicians, specialty consultants, pharmacist and allied health care professional needs to refine their approach to individual hypertensive patients and identify possible simplification strategies for periodic review of medication regimens to ascertain confounding factors that may adversely affect adherence. They need to educate and counsel the patients on importance of medication adherence, to avoid running out of medications and to adopt technology based medication aids.

This article focuses on the issue of medication adherence in Indian hypertensive patients in Navi Mumbai using a specific hypertension medication adherence scale (HILLBONE CHBPTS) and highlights the need to improve medication adherence in order to achieve optimal controlled blood pressure to prevent further hypertension related complications.

There were some limitations in our study. It was a quantitative study with a cross-sectional design. Study sample size was limited and conducted at a single hospital and not community-based therefore the findings cannot be generalized. Further multi-centric studies with larger 
sample size are warranted. In this study, medication adherence was assessed using HILL-BONE CHBPTS a subjective self-reporting scale therefore likely to be affected by recall bias and errors in self-observation. Other adherence methods like pill counting, refill compliance, medication event monitoring gadgets or drug blood estimation were not done.

\section{CONCLUSION}

Non-adherence to the therapeutic regimen remains a major limiting factor of hypertension management in India. Overall the medication adherence was poor in hypertensive patients. Poor adherence to therapy is largely unrecognized in clinical practice. Our study suggests that, improving medication adherence in hypertensive patients can help to achieve optimal blood pressure goals and prevent further hypertension related complications. Adherence to therapeutic regimens is an important factor for optimal clinical benefits; therefore efforts should be made by the physicians to identify the reasons for nonadherence and initiate steps to improve it.

\section{ACKNOWLEDGEMENTS}

Authors would like to thank Dr. Martha Hill and coauthors (Dr. Miyong Kim, Dr. Lee Bone and Dr. David Levine) for granting permission to use the hill-bone compliance to high blood pressure therapy scale and Dr. Jaishree Ghanekar (Head, Department of Medicine) for the support and co-operation.

Funding: No funding sources

Conflict of interest: None declared

Ethical approval: The study was approved by the Institutional Ethics Committee

\section{REFERENCES}

1. Kearney PM, Whelton M, Reynolds K, Muntner P, Whelton PK, He J. Global burden of hypertension: analysis of worldwide data. Lancet. 2005;365(9455):217-23.

2. Holt EW, Muntner P, Joyce CJ, Webber L, KrouselWood MA. Health-related quality of life and antihypertensive medication adherence among older adults. Age Ageing. 2010;39(4):481-7.

3. Kale S, Patil A, Mandlecha RH. Compliance and adverse drug effects of antihypertensives in rural India. J Clin Diagn Res. 2011;5(4):775-9.

4. Odili VU, Oghagbon EK, Ugwa NA, Ochei UM. Adherence to International guidelines in the management of hypertension in a tertiary hospital in Nigeria. Trop J Pharm Res. 2008;7(2):945-52.

5. Chelkeba L, Dessie S. Antihypertension medication adherence and associated factors at Dessie. Int J Res Med Sci. 2013;1(3):191-7.

6. Ong KL, Cheung BM, Man YB, Lau CP, Lam KS. Prevalence, awareness, treatment, and control of hypertension among United States adults 1999-2004. Hypertension. 2007;49(1):69-75.

7. Hyman DJ, Pavlik VN. Characteristics of patients with uncontrolled hypertension in the United States. N Engl J Med. 2001;345(7):479-86.

8. Anchala R, Kannuri NK, Pant H, Khan H, Franco $\mathrm{OH}$, Di Angelantonio E, et al. Hypertension in India: a systematic review and meta-analysis of prevalence, awareness, and control of hypertension. J Hypertens. 2014;32(6):1170-7.

9. Brown MT, Bussell JK. Medication Adherence: WHO Cares?. Mayo Clin Proc. 2011;86(4):304-14.

10. Ramli A, Ahmad NS, Paraidathathu T. Medication adherence among hypertensive patients of primary health clinics in Malaysia. Patient Prefer Adherence. 2012;6:613-22.

11. Khalil SA, Elzubier AG. Drug compliance among hypertensive patients in Tabuk, Saudi Arabia. J Hypertens. 1997;15(5):561-5.

12. Elzubier AG, Husain AA, Suleiman IA, Hamid ZA. Drug compliance among hypertensive patients in Kassala, eastern Sudan. East Mediterr Health J. 2000;6(1):100-5.

13. Osamor PE, Owumi BE. Factors associated with treatment compliance in hypertension in Southwest Nigeria. J Health Popul Nutr. 2011;29(6):619-28.

14. Delamater AM. Improving patient adherence. Clin Diabetes. 2006;24:71-7.

15. Meichenbaum D, Turk DC. Facilitating treatment adherence: a practitioner's Guidebook. New York, NY: Plenum Press; 1987.

16. Ho PM, Bryson CL, Rumsfeld JS. Medication adherence: its importance in cardiovascular outcomes. Circulation. 2009;119(23):3028-35.

17. Cramer JA, Roy A, Burrell A, Fairchild CJ, Fuldeore MJ, Ollendorf DA, et al. Medication compliance and persistence: terminology and definitions. Value Health. 2008;11(1):44-7.

18. Okoro RN, Ngong CK. Assessment of patient's antihypertensive medication adherence level in noncomorbid hypertension in a tertiary hospital in Nigeria. Int J Pharm Biomed Sci. 2012;3(2):47-54.

19. Biradar SS, Rajashekhar K, Srinivas R, Raju SA. Assessment of pharmacist mediated patient counseling on medication adherence in hypertension pateints of south Indian city. International Research Journal of Pharmacy. 2012;3:251-5.

20. Dennis T, Meera NK, Binny K, Sekhar MS, Kishore G, Sashidharan S. Medication adherence and associated barriers in hypertension management in India. CVD Prev Control. 2011;6(1):9-13.

21. Santra G. Assessment of adherence to cardiovascular medicines in rural population: an observational study in patients attending a tertiary care hospital. Indian $\mathbf{J}$ Pharmacol. 2015;47(6):600-4.

22. Navya CJ, Naveen R, Ashwini GS, Manu A, Steve J, Singh $\mathrm{J}$, et al. Adherence to medication among patients with hypertension and diabetes mellitus in selected tea estates in South India. JIMSA. 2015;28(1):16-17. 
23. Venkatachalam J, Abrahm SB, Singh Z, Stalin P, Sathya GR. Determinants of patient's adherence to hypertension medications in a rural population of Kancheepuram District in Tamil Nadu, South India. Indian J Community Med. 2015;40(1):33-7.

24. Kim MT, Hill MN, Bone LR and Levine DM. Development and testing of the hill-bone compliance to high blood pressure therapy scale. Prog Cardiovasc Nurs. 2000;15(3):90-6.

25. Lambert EV, Steyn K, Stender S, Everage N, Fourie JM, Hill M. Cross-cultural validation of the hill-bone compliance to high blood pressure therapy scale in a South African, primary healthcare setting. Ethn Dis. 2006;16(1):286-91.

26. Krousel-Wood M, Muntner P, Jannu A, Desalvo K, $\mathrm{Re}$ RN. Reliability of a medication adherence measure in an outpatient setting. Am J Med Sci. 2005;330(3):128-33.

27. Song Y, Han HR, Song HJ, Nam S, Nguyen T, Kim MT. Psychometric evaluation of hill-bone medication adherence subscale. Asian Nurs Res (Korean Soc Nurs Sci). 2011;5(3):183-8.

28. James PA, Oparil S, Carter BL, Cushman WC, Dennison-Himmelfarb C, Handler J, et al. Evidencebased guideline for the management of high blood pressure in adults: report from the panel members appointed to the eighth joint national committee (JNC 8). JAMA. 2014;311(5):507-20.

29. Mafutha GN, Wright SCD. Compliance or noncompliance of hypertensive adults to hypertension management at three primary healthcare day clinics in Tshwane. Curationis. 2013;36(1):E1-6.

30. Marshall IJ, Wolfe CD, McKevitt C. Lay perspectives on hypertension and drug adherence: systematic review of qualitative research. BMJ. 2012;345:e3953.

31. Krousel-Wood M, Thomas S, Muntner P, Morisky D. Medication adherence: a key factor in achieving blood pressure control and good clinical outcomes in hypertensive patients. Curr Opin Cardiol. 2004;19(4):357-62.

32. Jin J, Sklar GE, Min Sen Oh V, Chuen Li S. Factors affecting therapeutic compliance: A review from the patient's perspective. Ther Clin Risk Manag. 2008;4(1):269-86.

33. Grant RW, Devita NG, Singer DE, Meigs JB. Polypharmacy and medication adherence in patients with type 2 diabetes. Diabetes Care. 2003;26:140812.

34. Iihara N, Tsukamoto $\mathrm{T}$, Morita S, Miyoshi C, Takabatake K, Kurosaki Y. Beliefs of chronically ill
Japanese patients that lead to intentional nonadherence to medication. J Clin Pharm Ther. 2004;29:417-24.

35. Iskedjian M, Einarson TR, MacKeigan LD, Shear N, Addis A, Mittmann N, et al. Relationship between daily dose frequency and adherence to antihypertensive pharmacotherapy: evidence from a meta-analysis. Clin Ther. 2002;24:302-16.

36. Claxton AJ, Cramer J, Pierce C. A systematic review of the associations between dose regimens and medication compliance. Clin Ther. 2001;23:1296310.

37. Dhanireddy KK, Maniscalco J, Kirk AD. Is tolerance induction the answer to adolescent non-adherence? Pediatr Transplant. 2005;9:357-63.

38. Sharkness CM, Snow DA. The patient's view of hypertension and compliance. Am J Prev Med. 1992;8:141-6.

39. Caro JJ, Salas M, Speckman JL. Persistence with treatment for hypertension in actual practice. CMAJ. 1999;160:31-7.

40. Salanitro AH, Funkhouser E, Agee BS, Allison JJ, Halanych JH, Houston TK, et al. Multiple uncontrolled conditions and blood pressure medication intensification: an observational study. Implement Sci. 2010;5(55):1-9.

41. Zachariah MG, Thankappan KR, Alex SC, Sarma PS, Vasan RS. Prevalence, correlates, awareness, treatment, and control of hypertension in a middleaged urban population in Kerala. Indian Heart $\mathrm{J}$. 2003;55(3):245-51.

42. Weinberger MH, Glazer RD, Crikelair NA, Chiang YT. Achieving blood pressure goal: initial therapy with valsartan/hydrochlorothiazide combination compared with monotherapy. J Hum Hypertens. 2010;24(12):823-30.

43. Lalić J, Radovanović RV, Mitić B, Nikolić V, Spasić A, Koraćević G. Medication adherence in outpatients with arterial hypertension. Acta Facultatis Medicae Naissensis. 2013;30(4):209-18.

44. Khan GM, Thapa RK, Khakurel A, Shrestha G, Katila N, Bhurtel S. Medication adherence and blood pressure control among hypertensive patients of Pokhara valley. JHAS. 2013;3(1):64-7.

45. Gupta R, Guptha S. Strategies for initial management of hypertension. Indian J Med Res. 2010;132(5):53142.

46. Haynes JM, Sweeney EL. The effect of telephone appointment-reminder calls on outpatient absenteeism in a pulmonary function laboratory. Respir Care. 2006;51(1):36-9.

Cite this article as: Bhusal A, Jadhav PR,

Deshmukh YA. Assessment of medication adherence among hypertensive patients: a cross-sectional study. Int J Basic Clin Pharmacol 2016;5:1606-12. 